\title{
ON THE ROLE OF EXPECTATIONS IN COSTA RICAN BUSINESS CYCLE: AN ECONOMETRIC RESEARCH
}

\author{
Felipe A. Gómez Trejos ${ }^{1}$
}

Recibido: 20/02/2014 Aprobado: 22/04/2014

\begin{abstract}
Expectations formation of future output fluctuations as a factor for explaining Costa Rican business cycle is the main subject addressed in this paper. The main contribution of this research is the proposition of an econometric model for estimating the effect that an increase in the next quarter expected real GDP has on current quarterly real GDP level. To this end, a dynamic stochastic general equilibrium model is used as the theoretical base for explaining the nature of the causality relationship between expected output variability and economic fluctuations. Furthermore, a state-space representation of a Rational Expectations (R.E.) model is developed for constructing an expectations updating mechanism which fully characterizes the dynamics of the expected output variability. This investigation concludes that a 1\% increase in the next quarter's expected GDP is predicted to generate, on average, an approximate $0.67 \%$ growth on current quarterly GDP (in real terms). From this modeling perspective, the econometric analysis concludes this effect is statistically significant and also identifies other relevant factors for explaining Costa Rican business cycle, such as the forecasts of economics variables that determine output fluctuations throughout time.
\end{abstract}

KEYWORDS: EXPECTATIONS, DYNAMIC STOCHASTIC GENERAL EQUILIBRIUM MODEL, RATIONAL EXPECTATIONS MODEL, FORECAST, STATE-SPACE REPRESENTATION.

\section{RESUMEN}

El tema fundamental que se estudia en este artículo es la formación de expectativas sobre las fluctuaciones futuras en la producción como un factor clave para explicar el ciclo económico en Costa Rica. La principal contribución de esta investigación es la propuesta de un modelo econométrico para estimar el efecto que un incremento en el nivel esperado del PIB real para el siguiente trimestre ejerce sobre el PIB real del trimestre actual. Para este fin, un modelo Dinámico Estocástico de Equilibrio General se utiliza como base teórica para explicar la naturaleza de la relación de causalidad entre la variabilidad esperada en la producción y las fluctuaciones económicas. Además, un modelo de expectativas racionales en representación de espacio de estados se desarrolla para efectos de construir un mecanismo de actualización de expectativas que caracterice totalmente la dinámica de la variabilidad esperada en la producción. Esta investigación concluye que un incremento del $1 \%$ en el PIB esperado para el siguiente trimestre genera, en promedio, un 
aumento del $0.67 \%$ en el PIB trimestral actual (en términos reales). Desde esta perspectiva en que se modela el tema en cuestión, el análisis econométrico concluye que este efecto es estadísticamente significativo y también identifica otros factores relevantes para explicar el ciclo económico costarricense, tales como los pronósticos de variables económicas que determinan las fluctuaciones en la producción a lo largo del tiempo.

PALABRAS CLAVE: EXPECTATIVAS, MODELO DINÁMICO ESTOCÁSTICO DE EQUILIBRIO GENERAL, EXPECTATIVAS RACIONALES, PRONÓSTICO, REPRESENTACIÓN EN ESPACIO DE ESTADOS

\section{INTRODUCTION}

This paper investigates the effect that variations in future output expectations have on current output level, specifically for the case of Costa Rica ${ }^{2}$. The subject in question is relevant for practical purposes because of the possibility to achieve real effects through economic policy by appealing to convenient forms of announcing monetary or fiscal rules in order to modify agents' forecasts of economic variables. For instance, if expectations that economic agents (consumers, producers and government) have on future output (and in this way of their expected real income) adjust to perceived modifications of their environment, then these adjustments finally induce individuals to alter their production and saving decisions, which have real effects on the economy. Unfortunately, although research in this matter is useful and necessary in Costa Rica, it is also scarce. Therefore, the paper at hand is intended to narrow the gap between current investigation on the topic and real needs.

Regarding the structure of this paper, a short revision of literature is done in section II. Furthermore, an economic model which presents a causality relationship between the expected future output and the current observed level (i.e. the "output equation") will be derived in the first part of section III. This result is used in the second part of section III for developing a state-space representation of a rational expectations model for fully describing the dynamic behaviour of output's expectation. The main purpose of the paper will be achieved in this section, which is to propose an econometric model in order to empirically estimate the effect that variability on future output expectations has on the current output level. The corresponding estimation results are presented in section IV. Finally, concluding remarks shall be presented in section V.

\section{A BRIEF LITERATURE SURVEY}

Although the focus of this paper is not to make a revision of literature about the topic in question, some survey could be adequate for contextualizing the problem. There are three papers in particular which must be highlighted. Regarding the first one, Campbell and Mankiw (1986) estimated standard ARIMA processes for the real GNP (in logs) of the American economy using post-war quarterly time series ${ }^{3}$. Their objective was to test how persistent were output shocks in order to support their skepticism about all output fluctuations being "transitory". The investigation is relevant because it considered a model which implicitly suggested a relationship between realized output growth rates and expected output growth rates. Namely, their main conclusion was that unexpected changes of one percent in real GNP would change one's forecast of output growth by nearly one percent

$2 \quad$ As explained in section III, the time series analyzed to this end correspond to the period 1991-2012 (quarterly frequency).

See Campbell, J; Mankiw, G. "Are output fluctuations transitory?". 
over very long periods. This conclusion (according to the authors) suggested doubts about the transience of output shocks, because if output deviations from its natural level were temporary, then unexpected changes in current output should not affect one's forecast in long time periods. Furthermore, Beaudry and Koop $(1993)^{4}$ used an ARMA representation for modeling output growth in a similar fashion like Campbell and Mankiw (1986), but including also the possibility of asymmetric persistence in GNP. Their primary concern was to determine if positive and negative output shocks were equally persistent in the American economy. Their investigation proposed another methodology for analyzing the relationship between realized output growth rates and expected output growth rates. Specifically, the authors concluded that recessions affected output forecasts just eight to twelve quarters. Finally, it must be outlined the investigation conducted by Cerra and Saxena $(2008)^{5}$. The authors develop various AR representations of output in order to link output expectations with the occurrence of currency and financial crises, and currency and financial crises with output volatility. Therefore, their model describes an explicit causality relationship between output expectations and output volatility. Using panel data of a specific set of countries (Indonesia, Korea, Malaysia, Thailand, Argentina, Brazil, Chile, Mexico, Burundi, El Salvador, Nicaragua, Sierra Leone, and others) their research concluded that output expectations were significant for determining banking crises and in this way output fluctuations in countries included in the sample set.

All previous research underline different empirical methodologies for studying the relationship between expected output growth and realized output growth. However, the model used for addressing the topic in this paper avoids any ARIMA, ARMA or AR representation for accomplishing this end. The reason is because a less "atheoretical" and a more micro-based approach is desired in order not just to quantitatively determine the relationship in question, but also to provide a full theoretic characterization of the expectations mechanism that rules it. This is one of the contributions the present paper is expected to offer. Another relevant aspect to consider is that research in Costa Rica has fallen short in the study of these relationships, meanwhile the previous cited literature shows that it has been an important investigation topic in the macroeconomics research mainstream. Investigation like the one conducted by Castrillo and Torres (2010), Castrillo, Mora y Torres (2008) and Muñoz (2006) provide some insights of earlier research related to the specific topic of this paper, although none addressed this paper's main subject specifically. This implicates that another contribution of the present article is to narrow the gap between current investigation on the topic and real needs. Namely, the paper will draw conclusions on implications of the model's estimation results for monetary policy.

\section{METHODOLOGY}

\section{The economic model}

The theoretical derivation of the output equation presented in the subsequent analysis is based on the Sidrauski-Brock model developed by McCallum and Nelson (1997) ${ }^{6}$. Consider an infinitely-lived consumer which maximizes the discounted utility function

$4 \quad$ See Beaudry and Koop. "Do recessions permanently change output?".

$5 \quad$ See Cerra and Saxena. "Growth dynamics: the myth of economic recovery".

6 See McCallum, B., \& Nelson, E. (1997). "An optimizing IS-LM specification for monetary policy and business cycle analysis". It must be noted that this is a model of a Robinson Crusoe economy, so that aggregate demand of the only consumer (i.e. its consumption, capital and government expenses, and net exports) equals the aggregate demand of the whole economy. 
$\sum_{i=0}^{+\infty} \beta^{i} U\left(c_{t+i}, c_{t+i}^{f}, m_{t+i}\right)$. The variable $c_{t}$ designates its consumption of the compound good produced by the local economy, $c_{t}^{f}$ is the consumption of the compound good produced abroad, $m_{t}$ denotes the real money stock the individual holds at the beginning of period $t$ and $0<\beta<1$ is the discount factor. Also, the representative firm has access to a two-factor technology designated by the production function $y_{t}=f\left(n_{t}, k_{t}\right)$. In period labor and capital stock inputs ( $n_{t}$ and $k_{t}$ respectively) are used in the production process for generating output $y_{t}$. In addition, the representative firm hires each labor unit at the real wage $w_{t}$, sells its produced compound good at price level $P_{t}$, and exports a determined quantity of the produced compound good. Furthermore, the economy has a government sector which performs three specific activities in each period: i) collects a lump-sum tax $v_{t}$ from the representative consumer, ii) issues one-period bonds at a nominal interest rate $r_{t}\left(b_{t+1}\right.$ is the quantity of bonds the representative consumer buys in period $t$ and $b_{t+1}^{f}$ corresponds to foreign bonds acquired by the consumer in period $t$ ), and iii) buy a quantity $g_{t}$ of the locally produced compound good. Finally, consider $\pi_{t}=\frac{P_{t+1}-P_{t}}{P_{t}}$ the inflation rate, $0<\delta<1$ the physical capital depreciation rate, $P_{t}{ }^{*}$ the price level of the compound good produced abroad and $S_{t}$ is the nominal exchange rate (expressed as the price of foreign currency in terms of the local currency unit). Marginal utilities are assumed to be positive and decreasing with respect to $c_{t}$, $c_{t}^{f}, m_{t}$, and the available technology to satisfy the Inada conditions.

Thus, the output equation will be obtained from the solution of the individual's dynamic problem:

$$
\begin{gathered}
\max \quad U=E_{t}\left[\sum_{i=0}^{+\infty} \beta^{i} U\left(c_{t+i}, c_{t+i}^{f}, m_{t+i}\right)\right] \\
\text { s.t. } f\left(n_{t}, k_{t}\right)-v_{t}+x_{t}=c_{t}+k_{t+1}-(1-\delta) k_{t}+w_{t}\left(n_{t}-1\right)+\left(1+E_{t}\left(\pi_{t}\right)\right) m_{t+1}-m_{t} \\
+b_{t+1}\left(1+r_{t}\right)^{-1}-b_{t}+b_{t+1}^{f}\left(1+r_{t}\right)^{-1}-b_{t}^{f}+S_{t} \frac{P_{t}^{*}}{P_{t}} c_{t}^{f}
\end{gathered}
$$

and so, the associated Bellman equation is:

$$
\begin{aligned}
V\left(v_{t}, k_{t}, m_{t} w_{t}, r_{t}, E_{t}\left(\pi_{t}\right) b_{t}, b_{t}^{f}\right) \\
=\max _{\theta}\left\{U\left(c_{t}, c_{t}^{f}, m_{t}\right)\right. \\
\left.+E_{t}\left[\beta V\left(v_{t+1}, k_{t+1}, m_{t+1} w_{t+1}, r_{t+1}, E_{t+1}\left(\pi_{t+1}\right) b_{t+1}, b_{t+1}^{f}\right)\right]\right\} \\
\text { s.t. } \quad \theta=\left(c_{t}, c_{t}^{f}, m_{t+1}, n_{t}, b_{t+1}, b_{t+1}^{f}, k_{t+1}\right)
\end{aligned}
$$

Then, the Lagrangian function to maximize shall be:

$$
\begin{aligned}
\mathcal{L}=U\left(c_{t}, c_{t}^{f},\right. & \left.m_{t}\right)+E_{t}[\beta V] \\
& +\lambda_{t}\left[f\left(n_{t}, k_{t}\right)-v_{t}+x_{t}-c_{t}-k_{t+1}+(1-\delta) k_{t}-w_{t}\left(n_{t}-1\right)\right. \\
& -\left(1+E_{t}\left(\pi_{t}\right)\right) m_{t+1}+m_{t}-b_{t+1}\left(1+r_{t}\right)^{-1}+b_{t}-b_{t+1}^{f}\left(1+r_{t}\right)^{-1}+b_{t}^{f} \\
& \left.-S_{t} \frac{P_{t}^{*}}{P_{t}} c_{t}^{f}\right]
\end{aligned}
$$

After determining explicit expressions for the derivatives of the value function, a system of the following form is obtained: 


$$
\begin{aligned}
& f\left(n_{t}, k_{t}\right)-v_{t}+x_{t}=c_{t}+k_{t+1}-(1-\delta) k_{t}+w_{t}\left(n_{t}-1\right)+\left(1+E_{t}\left(\pi_{t}\right)\right) m_{t+1} \\
& -m_{t}+b_{t+1}\left(1+r_{t}\right)^{-1}-b_{t}+b_{t+1}^{f}\left(1+r_{t}\right)^{-1}-b_{t}^{f}+S_{t} \frac{P_{t}^{*}}{P_{t}} c_{t}^{f} \\
& \frac{\partial U}{\partial c_{t}}-\lambda_{t}=0 \\
& \beta E_{t}\left(\frac{\partial U}{\partial m_{t+1}}\right)-\lambda_{t}\left(1+E_{t}\left(\pi_{t}\right)\right)+\beta E_{t}\left(\lambda_{t+1}\right)=0 \\
& \beta E_{t}\left[\lambda_{t+1}\left(\frac{\partial f}{\partial k_{t+1}}+1-\delta\right)\right]-\lambda_{t}=0 \\
& \frac{\partial f}{\partial n_{t}}-w_{t}=0 \\
& \beta E_{t}\left(\lambda_{t+1}\right)-\lambda_{t}\left(1+r_{t}\right)^{-1}=0 \\
& \frac{\partial U}{\partial c_{t}^{f}}-\lambda_{t} S_{t} \frac{P_{t}^{*}}{P_{t}}=0
\end{aligned}
$$

It should be noted that in order to obtain an explicit output equation, then a more specific characterization of the consumer's preferences is required. To this end, consider the utility function:

$$
\begin{aligned}
U\left(c_{t}, c_{t}^{f}, m_{t}\right)= & \alpha_{1} \sigma(\sigma-1)^{-1} c_{t}^{\frac{\sigma-1}{\sigma}}+\alpha_{2} \chi\left(c_{t}^{f}\right)+\alpha_{3} \Psi\left(m_{t}\right) \\
& \sum_{p=1}^{3} \alpha_{p}=1 ; 0<\alpha_{p}<1 ; \chi^{\prime}>0 ; \chi^{\prime \prime}<0 ; \sigma>0
\end{aligned}
$$

Thus, to determine an output equation substitute (4) into (3):

$$
E_{t}\left(\frac{\partial U}{\partial m_{t+1}}\right)+E_{t}\left(\lambda_{t+1}\right)=E_{t}\left[\lambda_{t+1}\left(\frac{\partial f}{\partial k_{t+1}}+1-\delta\right)\right]\left(1+E_{t}\left(\pi_{t}\right)\right)
$$

Iterating (1) to period and substituting into the previous equation yields:

$$
E_{t}\left(\frac{\partial U}{\partial m_{t+1}}\right)+E_{t}\left(\frac{\partial U}{\partial c_{t+1}}\right)=E_{t}\left[\frac{\partial U}{\partial c_{t+1}}\left(\frac{\partial f}{\partial k_{t+1}}+1-\delta\right)\right]\left(1+E_{t}\left(\pi_{t}\right)\right)
$$

Use identity $E_{t}(m n)=E_{t}(m) E_{t}(n)+\operatorname{cov}_{t}(m, n)$ in the preceding equation and rearrange terms to obtain?

$$
E_{t}\left(\frac{\partial U}{\partial m_{t+1}}\right)=E_{t}\left(\frac{\partial U}{\partial c_{t+1}}\right)\left[E_{t}\left(\frac{\partial f}{\partial k_{t+1}}+1-\delta\right)\left(1+E_{t}\left(\pi_{t}\right)\right)-1\right]
$$

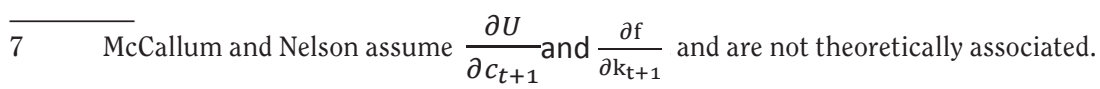


Next, replace (4) into (6):

$$
\beta E_{t}\left(\lambda_{t+1}\right)=\beta E_{t}\left[\lambda_{t+1}\left(\frac{\partial f}{\partial k_{t+1}}+1-\delta\right)\right]\left(1+r_{t}\right)^{-1}
$$

and invoke again $E_{t}(m n)=E_{t}(m) E_{t}(n)+\operatorname{cov}_{t}(m, n)$ to verify ${ }^{8}$ :

$$
\begin{gathered}
E_{t}\left(\lambda_{t+1}\right)=\beta E_{t}\left(\lambda_{t+1}\right) E_{t}\left(\frac{\partial f}{\partial k_{t+1}}+1-\delta\right)\left(1+r_{t}\right)^{-1} \\
\Leftrightarrow\left(1+r_{t}\right)=E_{t}\left(\frac{\partial f}{\partial k_{t+1}}+1-\delta\right)
\end{gathered}
$$

Now, substitute (2) into (4):

$$
\beta E_{t}\left[\frac{\partial U}{\partial c_{t+1}}\left(\frac{\partial f}{\partial k_{t+1}}+1-\delta\right)\right]-\frac{\partial U}{\partial c_{t}}=0
$$

Using identity $E_{t}(m n)=E_{t}(m) E_{t}(n)+\operatorname{cov}_{t}(m, n)$ in the previous equation, it can be verified that:

$$
\beta E_{t}\left(\frac{\partial U}{\partial c_{t+1}}\right) E_{t}\left(\frac{\partial f}{\partial k_{t+1}}+1-\delta\right)=\frac{\partial U}{\partial c_{t}}
$$

Replacing with (10):

$$
\beta E_{t}\left(\frac{\partial U}{\partial c_{t+1}}\right)\left(1+r_{t}\right)=\frac{\partial U}{\partial c_{t}}
$$

Now, derive (8) with respect to and substitute into (12):

$$
\beta E_{t}\left(\alpha_{1} c_{t+1}{ }^{-1 / \sigma}\right)\left(1+r_{t}\right)=\alpha_{1} c_{t}{ }^{-1 / \sigma}
$$

Log-linearize the previous expression by taking logs at both sides of the equation:

$$
\begin{array}{r}
\ln \left(\alpha_{1}\right)-\frac{1}{\sigma} \ln \left(c_{t}\right)=\ln (\beta)+\ln E_{t}\left(\alpha_{1} c_{t+1}{ }^{-\frac{1}{\sigma}}\right)+\ln \left(1+r_{t}\right) \\
\Leftrightarrow \ln \left(c_{t}\right)=\sigma \ln \left(\frac{\alpha_{1}}{\beta}\right)-\sigma \ln E_{t}\left(\alpha_{1} c_{t+1}-\frac{1}{\sigma}\right)-\sigma \ln \left(1+r_{t}\right)
\end{array}
$$

Additionally, introduce equation (2) into (7):

$$
\frac{\partial U}{\partial c_{t}^{f}}=\frac{\partial U}{\partial c_{t}} S_{t} \frac{P_{t}^{*}}{P_{t}}
$$

Derive (8) with respect to $c_{t}^{f}$ and replace into this last expression to prove:

$$
\begin{gathered}
\frac{\alpha_{2}}{\alpha_{1}} \chi^{\prime}\left(c_{t}^{f}\right) c_{t}^{\frac{-1}{\sigma}}=Q_{t} \text { tq } Q_{t}=S_{t} \frac{P_{t}^{*}}{P_{t}} \\
\Leftrightarrow c_{t}^{f}=h\left(Q_{t}, c_{t}\right) ; h_{1}<0, h_{2}>0
\end{gathered}
$$

$\overline{8} \quad$ At this point, McCallum and Nelson (1997) assumed $\lambda_{\mathrm{t}+1}$ and $\frac{\partial \mathrm{f}}{\partial \mathrm{k}_{\mathrm{t}+1}}$ were not theoretically associated. 
Notice (13) is the consumer's demand for the foreign consumption good, which corresponds to its imports function. Here, imports depend on the consumption of the locally produced good and the real exchange rate. Furthermore, by assuming that in the external sector exists another representative consumer that independently solves the same maximization problem and has preferences given by:

$$
\begin{gathered}
U\left(c_{t}^{*}, c_{t}^{f *}, m_{t}^{*}\right)=\varsigma_{1} \sigma(\sigma-1)^{-1}\left(c_{t}^{*}\right)^{\frac{\sigma-1}{\sigma}}+\varsigma_{2} \omega\left(c_{t}^{f *}\right)+\varsigma_{3} \Psi\left(m_{t}^{*}\right) \\
t q \sum_{p=1}^{3} \varsigma_{p}=1 ; 0<\varsigma_{p}<1 ; \omega^{\prime}>0 ; \omega^{\prime \prime}<0 ; \sigma>0
\end{gathered}
$$

an exports function can be determined. Since $c_{t}^{f *}=x_{t}$, then the external sector's solution to its own maximization problem produces an analogous criterion to (13), namely:

$$
x_{t}=\xi\left(Q_{t}, c_{t}^{*}\right) ; \xi_{1}>0, \xi_{2}<0
$$

Here, equation (14) designates the exports function of the local economy. Following McCallum and Nelson (1997), consider the identity $y=c+i+g+x-h$ in a log-version form ${ }^{9}$ :

$$
\begin{gathered}
\ln \left(y_{t}\right)=\gamma_{1} \ln \left(c_{t}\right)+\gamma_{2} \ln \left(i_{t}\right)+\gamma_{3} \ln \left(g_{t}\right)+\gamma_{4} \ln \left(x_{t}\right)-\gamma_{5} \ln \left(h_{t}\right) \\
\gamma_{l}>0 \forall l=1, \ldots, 5
\end{gathered}
$$

At this point, because the time path of is endogenously determined by solving the system given by equations (1)-(7) and equilibrium conditions ${ }^{10}$, then per capita investment expenditure is known form the expression $i_{t}=k_{t+1}-(1-\delta) k_{t}{ }^{11}$. Hence, replacing (12), (13), and (14) into (15) yields:

$$
\begin{aligned}
\ln \left(y_{t}\right)=\gamma_{1}[\sigma & \left.\ln \left(\frac{\alpha_{1}}{\beta}\right)-\sigma \ln E_{t}\left(\alpha_{1} c_{t+1}-\frac{1}{\sigma}\right)-\sigma \ln \left(1+r_{t}\right)\right]+\gamma_{2} \ln \left(i_{t}\right)+\gamma_{3} \ln \left(g_{t}\right) \\
& +\gamma_{4} \ln \xi\left(Q_{t}, c_{t}^{*}\right) \\
& \quad-\gamma_{5} \ln h\left(Q_{t}, c_{t}\right) \\
\Rightarrow \ln \left(y_{t}\right)=\gamma_{1}\{\sigma & \left.\ln \left(\frac{\alpha_{1}}{\beta}\right)-\sigma \ln E_{t}\left[\alpha_{1}\left(\phi y_{t+1}\right)^{-\frac{1}{\sigma}}\right]-\sigma \ln \left(1+r_{t}\right)\right\}+\gamma_{2} \ln \left(i_{t}\right)+\gamma_{3} \ln \left(g_{t}\right) \\
+ & \gamma_{4} \ln \xi\left(Q_{t}, c_{t}^{*}\right)-\gamma_{5} \ln h\left(Q_{t}, c_{t}\right) \\
\Leftrightarrow \ln \left(y_{t}\right)=\lambda_{0} & +\lambda_{1} \ln E_{t}\left(y_{t+1}^{-1 / \sigma}\right)+\lambda_{2} \ln \left(1+r_{t}\right)+\lambda_{3} \ln \vartheta\left(k_{t+1}, k_{t}\right)+\lambda_{4} \ln \left(g_{t}\right) \\
& +\lambda_{5} \ln \xi\left(Q_{t}, c_{t}^{*}\right)+\lambda_{6} \ln h\left(Q_{t}, c_{t}\left(y_{t+1}, r_{t}\right)\right)
\end{aligned}
$$

$9 \quad$ It is possible to show that the economy's resource constraint is obtained from the government's and consumer's budget constraints, and by imposing equilibrium conditions. See McCallum and Nelson (1997).

10 It is not of interest in this paper to solve for the time paths of each of the endogenous variables in this theoretic model. For details of these solutions, see McCallum and Nelson (1997).

The time path for is defined exogenously. 
In equation (I), $\phi \in(0,1)$ designates the steady-state average proportion that $c_{t}$ represents of $y_{t}$ Specifically, McCallum and Nelson (1997) establish the existence of steady state values for all variables in equation (15). Define $c^{*}$ and $y^{*}$ as the steady-state values of consumption and output, respectively. Then, an immediate consequence of (15) is that $\phi=\frac{c^{*}}{y^{*}} \in(0,1)$. Notice also that (I) constitutes the explicit form of the desired output equation. It establishes that current output depends on government's expenditure, the physical capital's stock dynamics, the real exchange rate and interest rate, the external sector's consumption of the compound good produced abroad, and next period's output level (from which the representative consumer formulates an expectation considering that in period $t$ it is an unknown and random variable). Therefore, the individual's next period output expectation directly affects current output level in the sense that marginal utilities from consuming in periods $t$ and $t+1$ are both positive and decreasing, so that an increase in the expected future income is reallocated between both periods via a savings adjustment in order to satisfy the Euler condition given by (12).

Finally, for purposes of econometric estimation, it is convenient to express the term $h\left(Q_{t}, y_{t+1}, r_{t}\right)$ in equation (I) as a function of its determinant factors $Q_{t}, y_{t+1}$ and $r_{t}{ }^{12}$. To this end, recall that consumer's preferences were given by the utility function:

$$
U\left(c_{t}, c_{t}^{f}, m_{t}\right)=\alpha_{1} \sigma(\sigma-1)^{-1} c_{t}^{\frac{\sigma-1}{\sigma}}+\alpha_{2} \chi\left(c_{t}^{f}\right)+\alpha_{3} \Psi\left(m_{t}\right)
$$

Now, by assuming the specification $\chi\left(c_{t}^{f}\right)=\sigma(\sigma-1)^{-1}\left(c_{t}^{f}\right)^{\frac{\sigma-1}{\sigma}}$, it is possible to obtain the derivative:

$$
\chi^{\prime}\left(c_{t}^{f}\right)=\left(c_{t}^{f}\right)^{\frac{-1}{\sigma}}
$$

Substituting in the expression $\frac{\partial \mathrm{U}}{\partial \mathrm{c}_{\mathrm{t}}^{\mathrm{f}}}=\frac{\partial \mathrm{U}}{\partial \mathrm{c}_{\mathrm{t}}} \mathrm{S}_{\mathrm{t}} \frac{\mathrm{P}_{\mathrm{t}}^{*}}{\mathrm{P}_{\mathrm{t}}}$ with the appropriate derivatives and equating $Q_{t}=S_{t} \frac{P_{t}^{*}}{P_{t}}$ yields:

$$
\alpha_{2}\left(c_{t}^{f}\right)^{\frac{-1}{\sigma}}=\alpha_{1} c_{t} \frac{-1}{\sigma} Q_{t}
$$

Log-linearize this equation and rearrange to verify (recall that $c_{t}^{f}=h_{t}$ ):

$$
\ln h_{t}=-\sigma \ln \left(\frac{\alpha_{1}}{\alpha_{2}}\right)+\ln c_{t}-\sigma \ln Q_{t}
$$

12 The reason of this is because there exists a positive statistic association between imports and output in period $t$ (output depends on imports but at the same time imports depend on output), although it is theoretically known that imports represent a filtration in aggregate spending, and thus are negatively related. Specifically, the time series (in first differences) for the Costa Rican case used for this paper showed that the Pearson correlation coefficient for quarterly GDP and imports was around 0,3. This fact will condition the sign of the estimated parameter associated to $\ln \mathrm{h}$, and thus is more convenient to express equation (II) in order for the econometric model to explain quarterly GDP variability using the determinant factors of imports (known from the analytic model)rather than imports itself. 
Notice that (19) designates a particular specification of (14). Hence, using (13), (17), and (19) in an analogous procedure as the one used to determine the output equation (I), it is proven that:

$$
\begin{aligned}
\ln \left(y_{t}\right)=\lambda_{0}{ }^{\prime}+ & \lambda_{1}{ }^{\prime} \ln E_{t}\left(y_{t+1}{ }^{-1 / \sigma}\right)+\lambda_{2}{ }^{\prime} \ln \left(1+r_{t}\right)+\lambda_{3} \ln \vartheta\left(k_{t+1}, k_{t}\right)+\lambda_{4} \ln \left(g_{t}\right)+\lambda_{5} \ln \xi\left(Q_{t}, c_{t}^{*}\right) \\
& +\lambda_{6}{ }^{\prime} \ln Q_{t}
\end{aligned}
$$

Therefore, equation (19) is a particular case of expression (I) given the utility function specification from which (17) was obtained. And so, equation (19) shall be used as the starting point for fully defining the econometric model of next section ${ }^{13}$.

\section{The econometric model}

Recall that the purpose of this paper is to estimate the effect that variations in the forecast of future output have on current output determination in Costa Rica. To this end, equation (19) from the preceding section will be used as a starting point. Specifically, consider the model ${ }^{14}$ :

$$
\begin{aligned}
\ln \left(y_{t}\right)=\lambda_{0}+ & \lambda_{1} E_{t}\left[\ln \left(y_{t+1}\right)\right]+\lambda_{2} \ln \left(1+r_{t}\right)+\lambda_{3} \ln \left(i_{t}\right)+\lambda_{4} \ln \left(g_{t}\right)+\lambda_{5} \ln \left(x_{t}\right) \\
& +\lambda_{6} \ln \left(Q_{t}\right)
\end{aligned}
$$

Notice that $E_{t}\left[\ln \left(y_{t+1}\right)\right]$ in equation (20) is not an observable variable because it corresponds to the expectation agents formulate, given the information available in period $t$, of another variable which at period $t$ is still undetermined. This inherent randomness of $E_{t}\left[\ln \left(y_{t+1}\right)\right]$ implies the necessity of specifying a law of motion that governs the dynamics of throughout time. To this end, a state-space representation of a rational expectations (R.E.) model for $E_{t}\left[\ln \left(y_{t+1}\right)\right]$ shall be used for analyzing its dynamic behavior ${ }^{15}$.

13 Although it is well known that exports depend on the real exchange rate(generating a possible source of multicollinearity among these two explanatory variables and in the econometric estimation), it is also known from the analytic model that depends on both the real exchange rate and the consumption from the external sector of the good produced abroad. This last variable is not observable because it arises from an abstraction in which there only exist a local and a foreign economy. However, dropping it off the econometric model would lead to a specification bias due to omitted relevant variables (considering that in the real world this variable is conditioned by the economic activity levels of trading partners, which are essential for determining the local economy's exports). In reference to the issue of multicollinearity, Gruem and Shuetrim (1994) realized a similar experiment at which they constructed an econometric model in order to explain the Australian business cycle using as explanatory variables the first differences of the real exchange rate and the terms of trade (beside others) time series, although knowing that variability in the real exchange rate not coming from the nominal exchange rate indeed came from variability in the terms of trade (see Gruen,D., Shuetrim, G. (1994). "Internationalisation and the macroeconomy"). Their estimation concluded that foreign income level was statistically significant for explaining Australian business cycle. Given that in this case the exports variable contains the effect in due to foreign economic activity level, it is necessary to estimate the model considering exports as another regressor.

14 For the sake of clarity, lambda parameters were adopted for notational convenience. However, they are not being used to designate the same parameters of equation (II) from the previous section (notice that independent variables are different in each equation).

For details on the theoretic construction for a state-space representation of a rational expectations model of multiple endogenous and exogenous variables see Gourieroux \& Monfort(1997), pp. 622. Naturally, the R.E. model used in this paper proves to be more consistent and plausible from the theoretic point of view than any other adaptive expectations model. This is because the R.E. construction allows to econometrically model expectations dynamics under the assumption that agents use efficiently all available information. 
Notice that the expectation of $\ln \left(y_{t+1}\right)$ is the only variable whose forecast is of interest to explain, so that it is the only endogenous variable within the R.E. model. Following Gourieroux $\&$ Monfort (1997), all other exogenous variables (i.e. all other regressors in (20) different from $\left.E_{t}\left[\ln \left(y_{t+1}\right)\right]\right)$ are assumed to satisfy an $\mathrm{AR}(1)$ process.

This means that the dynamic behavior of is $\left(y_{t}\right)$ determined by $(20)$ and the following system of $\mathrm{AR}(1)$ processes denoted by (A):

$$
\left\{\begin{array}{c}
\ln \left(1+r_{t}\right)=\rho_{\mathrm{r}} \ln \left(1+r_{t-1}\right)+\varepsilon_{\mathrm{t}}^{\mathrm{r}} \\
\ln \left(i_{t}\right)=\rho_{\mathrm{i}} \ln \left(i_{t-1}\right)+\varepsilon_{\mathrm{t}}^{\mathrm{i}} \\
\ln \left(g_{t}\right)=\rho_{\mathrm{g}} \ln \left(g_{t-1}\right)+\varepsilon_{\mathrm{t}}^{\mathrm{g}} \\
\ln \left(x_{t}\right)=\rho_{\mathrm{x}} \ln \left(x_{t-1}\right)+\varepsilon_{\mathrm{t}}^{\mathrm{x}} \\
\ln \left(Q_{t}\right)=\rho_{\mathrm{q}} \ln \left(Q_{t-1}\right)+\varepsilon_{\mathrm{t}}^{\mathrm{q}}
\end{array}\right.
$$

The next step is to invoke the assumption of R.E. in order to define the relationship between expectations and realizations as indicated in (21) and system $(\mathrm{B})^{16}$ :

$$
\left\{\begin{array}{c}
\ln \left(y_{t}\right)=\mathrm{E}_{\mathrm{t}-1}\left[\ln \left(\mathrm{y}_{\mathrm{t}}\right)\right]+\varepsilon_{\mathrm{t}}^{\mathrm{y}} \\
\ln \left(1+r_{t}\right)=\mathrm{E}_{\mathrm{t}-1}\left[\ln \left(1+r_{t}\right)\right]+\varepsilon_{\mathrm{t}}^{\mathrm{r}} \\
\ln \left(i_{t}\right)=\mathrm{E}_{\mathrm{t}-1}\left[\ln \left(i_{t}\right)\right]+\varepsilon_{\mathrm{t}}^{\mathrm{i}} \\
\ln \left(g_{t}\right)=\mathrm{E}_{\mathrm{t}-1}\left[\ln \left(g_{t}\right)\right]+\varepsilon_{\mathrm{t}}^{\mathrm{g}} \\
\ln \left(x_{t}\right)=\mathrm{E}_{\mathrm{t}-1}\left[\ln \left(x_{t}\right)\right]+\varepsilon_{\mathrm{t}}^{\mathrm{x}} \\
\ln \left(Q_{t}\right)=\mathrm{E}_{\mathrm{t}-1}\left[\ln \left(Q_{t}\right)\right]+\varepsilon_{\mathrm{t}}^{\mathrm{q}}
\end{array}\right.
$$

Substitute (21) into (20) and solve for $\mathrm{E}_{\mathrm{t}}\left[\ln \left(\mathrm{y}_{\mathrm{t}+1}\right)\right]$ in order to get:

$$
\begin{aligned}
\mathrm{E}_{\mathrm{t}}\left[\ln \left(\mathrm{y}_{\mathrm{t}+1}\right)\right]= & \lambda_{1}^{-1} \mathrm{E}_{\mathrm{t}-1}\left[\ln \left(\mathrm{y}_{\mathrm{t}}\right)\right] \\
& -\lambda_{1}^{-1}\left[\lambda_{0}+\lambda_{2} \ln \left(1+r_{t}\right)+\lambda_{3} \ln \left(i_{t}\right)+\lambda_{4} \ln \left(g_{t}\right)+\lambda_{5} \ln \left(x_{t}\right)+\lambda_{6} \ln \left(Q_{t}\right)\right] \\
& +\lambda_{1}^{-1} \varepsilon_{\mathrm{t}}^{\mathrm{y}}
\end{aligned}
$$

Next, replace in the previous expression all realizations of exogenous variables with the equations of system (B) accordingly to each variable to verify:

16 Notice that forecast error terms in (B) are the same as the ones in (A), which means that error terms in (B) satisfy all white noise properties. Additionally, a direct consequence of the R.E. assumption is that is zero mean and temporally uncorrelated with $\varepsilon_{\tau}^{\mathrm{y}}$ and $\varepsilon_{\tau}^{\kappa}(\tau \neq \mathrm{t})$, where $\kappa$ denotes any of the exogenous variables. 


$$
\begin{aligned}
\mathrm{E}_{\mathrm{t}}\left[\ln \left(\mathrm{y}_{\mathrm{t}+1}\right)\right]= & -\lambda_{1}^{-1} \lambda_{0}+\lambda_{1}^{-1} \mathrm{E}_{\mathrm{t}-1}\left[\ln \left(\mathrm{y}_{\mathrm{t}}\right)\right]-\lambda_{1}^{-1} \lambda_{2} \mathrm{E}_{\mathrm{t}-1}\left[\ln \left(1+r_{t}\right)\right]-\lambda_{1}^{-1} \lambda_{3} \mathrm{E}_{\mathrm{t}-1}\left[\ln \left(i_{t}\right)\right] \\
& -\lambda_{1}^{-1} \lambda_{4} \mathrm{E}_{\mathrm{t}-1}\left[\ln \left(g_{t}\right)\right]-\lambda_{1}^{-1} \lambda_{5} \mathrm{E}_{\mathrm{t}-1}\left[\ln \left(x_{t}\right)\right]-\lambda_{1}^{-1} \lambda_{6} \mathrm{E}_{\mathrm{t}-1}\left[\ln \left(Q_{t}\right)\right] \\
& \quad-\lambda_{1}^{-1}\left[\lambda_{2} \varepsilon_{\mathrm{t}}^{\mathrm{r}}+\lambda_{3} \varepsilon_{\mathrm{t}}^{\mathrm{i}}+\lambda_{4} \varepsilon_{\mathrm{t}}^{\mathrm{g}}+\lambda_{5} \varepsilon_{\mathrm{t}}^{\mathrm{x}}+\lambda_{6} \varepsilon_{\mathrm{t}}^{\mathrm{q}}\right]+\lambda_{1}^{-1} \varepsilon_{\mathrm{t}}^{\mathrm{y}} \\
\Rightarrow \mathrm{E}_{\mathrm{t}}\left[\ln \left(\mathrm{y}_{\mathrm{t}+1}\right)\right]= & \beta_{0}+\beta_{1} \mathrm{E}_{\mathrm{t}-1}\left[\ln \left(\mathrm{y}_{\mathrm{t}}\right)\right]+\beta_{2} \mathrm{E}_{\mathrm{t}-1}\left[\ln \left(1+r_{t}\right)\right]+\beta_{3} \mathrm{E}_{\mathrm{t}-1}\left[\ln \left(i_{t}\right)\right]+\beta_{4} \mathrm{E}_{\mathrm{t}-1}\left[\ln \left(g_{t}\right)\right] \\
+ & \beta_{5} \mathrm{E}_{\mathrm{t}-1}\left[\ln \left(x_{t}\right)\right]+\beta_{6} \mathrm{E}_{\mathrm{t}-1}\left[\ln \left(Q_{t}\right)\right] \\
+ & \omega_{t}
\end{aligned}
$$

where

$$
\omega_{t}=-\lambda_{1}^{-1}\left[\lambda_{2} \varepsilon_{\mathrm{t}}^{\mathrm{r}}+\lambda_{3} \varepsilon_{\mathrm{t}}^{\mathrm{i}}+\lambda_{4} \varepsilon_{\mathrm{t}}^{\mathrm{g}}+\lambda_{5} \varepsilon_{\mathrm{t}}^{\mathrm{x}}+\lambda_{6} \varepsilon_{\mathrm{t}}^{\mathrm{q}}\right]+\lambda_{1}^{-1} \varepsilon_{\mathrm{t}}^{\mathrm{y}}
$$

A similar procedure allows rewriting system (A) in a convenient fashion for fully characterizing the dynamic behavior of the exogenous variables forecasts'. To this end, substitute realizations of exogenous variables in (A) with the expressions of system (B) accordingly to each variable, and solve for the expectation term conditional on information in period $t-1$ in order to obtain system $(\mathrm{C})$ :

$$
\left\{\begin{aligned}
\mathrm{E}_{\mathrm{t}-1}\left[\ln \left(1+r_{t}\right)\right] & =\rho_{\mathrm{r}} \mathrm{E}_{\mathrm{t}-2}\left[\ln \left(1+r_{t-1}\right)\right]+\rho_{\mathrm{r}} \varepsilon_{\mathrm{t}-1}^{\mathrm{r}} \\
\mathrm{E}_{\mathrm{t}-1}\left[\ln \left(i_{t}\right)\right] & =\rho_{\mathrm{i}} \mathrm{E}_{\mathrm{t}-2}\left[\ln \left(i_{t-1}\right)\right]+\rho_{\mathrm{i}} \varepsilon_{\mathrm{t}-1}^{\mathrm{i}} \\
\mathrm{E}_{\mathrm{t}-1}\left[\ln \left(g_{t}\right)\right] & =\rho_{\mathrm{g}} \mathrm{E}_{\mathrm{t}-2}\left[\ln \left(g_{t-1}\right)\right]+\rho_{\mathrm{g}} \varepsilon_{\mathrm{t}-1}^{\mathrm{g}} \\
\mathrm{E}_{\mathrm{t}-1}\left[\ln \left(x_{t}\right)\right] & =\rho_{\mathrm{x}} \mathrm{E}_{\mathrm{t}-2}\left[\ln \left(x_{t-1}\right)\right]+\rho_{\mathrm{x}} \varepsilon_{\mathrm{t}-1}^{\mathrm{x}} \\
\mathrm{E}_{\mathrm{t}-1}\left[\ln \left(Q_{t}\right)\right] & =\rho_{\mathrm{q}} \mathrm{E}_{\mathrm{t}-2}\left[\ln \left(Q_{t-1}\right)\right]+\rho_{\mathrm{q}} \varepsilon_{\mathrm{t}-1}^{\mathrm{q}}
\end{aligned}\right.
$$

Therefore, the complete model to be estimated is determined by equations (20), (22), and system (C). Observe that equations from system (C) have been numbered for the sake of clarity and order in the presentation of estimation results ${ }^{17}$.

$$
\begin{aligned}
\ln \left(y_{t}\right)=\lambda_{0}+ & \lambda_{1} E_{t}\left[\ln \left(y_{t+1}\right)\right]+\lambda_{2} \ln \left(1+r_{t}\right)+\lambda_{3} \ln \left(i_{t}\right)+\lambda_{4} \ln \left(g_{t}\right)+\lambda_{5} \ln \left(x_{t}\right) \\
& +\lambda_{6} \ln \left(Q_{t}\right)
\end{aligned}
$$

17 Following Gourieroux \& Monfort (1997), expressions (23)-(27) have been iterated one period forward for estimation purposes. 


$$
\begin{aligned}
\mathrm{E}_{\mathrm{t}}\left[\ln \left(\mathrm{y}_{\mathrm{t}+1}\right)\right]= & \beta_{0}+\beta_{1} \mathrm{E}_{\mathrm{t}-1}\left[\ln \left(\mathrm{y}_{\mathrm{t}}\right)\right]+\beta_{2} \mathrm{E}_{\mathrm{t}-1}\left[\ln \left(1+r_{t}\right)\right]+\beta_{3} \mathrm{E}_{\mathrm{t}-1}\left[\ln \left(i_{t}\right)\right]+\beta_{4} \mathrm{E}_{\mathrm{t}-1}\left[\ln \left(g_{t}\right)\right] \\
& +\beta_{5} \mathrm{E}_{\mathrm{t}-1}\left[\ln \left(x_{t}\right)\right]+\beta_{6} \mathrm{E}_{\mathrm{t}-1}\left[\ln \left(Q_{t}\right)\right] \\
& +\omega_{t} \\
\mathrm{E}_{\mathrm{t}}\left[\ln \left(1+r_{t+1}\right)\right]=\rho_{\mathrm{r}} \mathrm{E}_{\mathrm{t}-1}\left[\ln \left(1+r_{t}\right)\right]+\rho_{\mathrm{r}} \varepsilon_{\mathrm{t}}^{\mathrm{r}} & \\
\mathrm{E}_{\mathrm{t}}\left[\ln \left(i_{t+1}\right)\right]= & \rho_{\mathrm{i}} \mathrm{E}_{\mathrm{t}-1}\left[\ln \left(i_{t}\right)\right]+\rho_{\mathrm{i}} \varepsilon_{\mathrm{t}}^{\mathrm{i}} \\
\mathrm{E}_{\mathrm{t}}\left[\ln \left(g_{t+1}\right)\right]= & \rho_{\mathrm{g}} \mathrm{E}_{\mathrm{t}-1}\left[\ln \left(g_{t}\right)\right]+\rho_{\mathrm{g}} \varepsilon_{\mathrm{t}}^{\mathrm{g}} \\
\mathrm{E}_{\mathrm{t}}\left[\ln \left(x_{t+1}\right)\right]= & \rho_{\mathrm{x}} \mathrm{E}_{\mathrm{t}-1}\left[\ln \left(x_{t}\right)\right]+\rho_{\mathrm{x}} \varepsilon_{\mathrm{t}}^{\mathrm{x}} \\
\mathrm{E}_{\mathrm{t}}\left[\ln \left(Q_{t+1}\right)\right]= & \rho_{\mathrm{q}} \mathrm{E}_{\mathrm{t}-1}\left[\ln \left(Q_{t}\right)\right]+\rho_{\mathrm{q}} \varepsilon_{\mathrm{t}}^{\mathrm{q}}
\end{aligned}
$$

Before proceeding with the presentation of estimation results, three important aspects should be highlighted about the R.E. model given by equations (20) and (22)-(27). First, notice that expressions (22)-(27) determine both an expectation updating mechanism and the causal relationships between exogenous variables' expectations (lagged) and $E_{t}\left[\ln \left(y_{t+1}\right)\right]$, which ultimately affects $\ln \left(y_{t}\right)$. Specifically, by defining the following vectors in $\mathbb{R}^{6}$ :

$$
\begin{aligned}
& z_{t}^{\prime}=\left(\mathrm{E}_{\mathrm{t}-1}\left[\ln \left(\mathrm{y}_{\mathrm{t}}\right)\right], \mathrm{E}_{\mathrm{t}-1}\left[\ln \left(1+r_{t}\right)\right], \mathrm{E}_{\mathrm{t}-1}\left[\ln \left(i_{t}\right)\right], \mathrm{E}_{\mathrm{t}-1}\left[\ln \left(g_{t}\right)\right], \mathrm{E}_{\mathrm{t}-1}\left[\ln \left(x_{t}\right)\right], \mathrm{E}_{\mathrm{t}-1}\left[\ln \left(Q_{t}\right)\right]\right)^{\prime} \\
& \varepsilon_{t}^{\prime}=\left(\varepsilon_{\mathrm{t}}^{\mathrm{y}}, \varepsilon_{\mathrm{t}}^{\mathrm{r}}, \varepsilon_{\mathrm{t}}^{\mathrm{i}}, \varepsilon_{\mathrm{t}}^{\mathrm{g}}, \varepsilon_{\mathrm{t}}^{\mathrm{x}}, \varepsilon_{\mathrm{t}}^{\mathrm{q}}\right)^{\prime} \\
& b^{\prime}=\left(\lambda_{0}, \lambda_{2}, \lambda_{3}, \lambda_{4}, \lambda_{5}, \lambda_{6}\right)^{\prime}
\end{aligned}
$$

and the matrix

$$
\Phi=\left(\rho_{i j}\right)_{5 \times 5}
$$

where

$$
\rho_{i j}=\left\{\begin{array}{c}
\rho_{\mathrm{r}} \text { if } \mathrm{i}=\mathrm{j}=1 \\
\rho_{\mathrm{i}} \text { if } \mathrm{i}=\mathrm{j}=2 \\
\rho_{\mathrm{g}} \text { if } \mathrm{i}=\mathrm{j}=3 \\
\rho_{\mathrm{x}} \text { if } \mathrm{i}=\mathrm{j}=4 \\
\rho_{\mathrm{q}} \text { if } \mathrm{i}=\mathrm{j}=5 \\
0 \text { if } \mathrm{i} \neq \mathrm{j}
\end{array}\right.
$$

then it is possible to rewrite (22)-(27) as a state equation of the form:

$$
z_{t+1}=\left(\begin{array}{cc}
\lambda_{1}^{-1} & -\lambda_{1}^{-1} b^{\prime} \\
0 & \Phi
\end{array}\right) z_{t}+\left(\begin{array}{cc}
\lambda_{1}^{-1} & -\lambda_{1}^{-1} b^{\prime} \\
0 & \Phi
\end{array}\right) \varepsilon_{t}
$$

with $z_{t}$ as the vector of state variables. This justifies the fact that the model about to be estimated is a state-space representation of an R.E. model, and implies that the dynamics of $\ln \left(y_{t}\right)$ can 
be fully characterized by expression (20) and a state equation given by (28), which rules the evolution of expectations throughout time. Another aspect to be highlighted is the fact that the stochastic specification of forecast errors may rule out the possibility of any theoretical evidence of autocorrelation and heteroskedasticity. As previously mentioned, both $\varepsilon_{t}^{\mathrm{y}}$ and $\varepsilon_{\mathrm{t}}^{\mathrm{k}}$ are zero mean and temporally uncorrelated with $\varepsilon_{\mathrm{T}}^{\mathrm{y}}$ and $\varepsilon_{\mathrm{T}}^{\mathrm{K}}(\mathrm{T} \neq \mathrm{t})$, where subscript $\mathrm{K}$ denotes any of the exogenous variables. Even so, $\varepsilon_{\mathrm{t}}^{\mathrm{y}}$ and $\varepsilon_{\mathrm{t}}^{\mathrm{k}}$ could be correlated and the model does not impose a priori any restriction on the variance of $\varepsilon_{\mathrm{t}}^{\mathrm{y}}$. Following Gourieroux \& Monfort (1997), by assuming a linear stationary relationship between innovations for the present case, i.e $e^{18}$.

$$
\varepsilon_{\mathrm{t}}^{\mathrm{y}}=\sum_{\mathrm{K}} \Pi_{\mathrm{K}} \varepsilon_{\mathrm{t}}^{\mathrm{K}}+\mathrm{u}_{\mathrm{t}} ; \operatorname{var}\left(\mathrm{u}_{\mathrm{t}}\right)=\Omega
$$

it can be shown that $\operatorname{cov}\left(\omega_{t}, \omega_{t-s}\right)=0$ and $\operatorname{var}\left(\omega_{t}\right) \in \mathbb{R}^{+}$, so that there is no autocorrelation nor heteroskedasticity arising from forecast errors. The last aspect to be highlighted refers to the procedure used for computing the expectation vectors for both the endogenous and exogenous variables. In this matter, it is assumed that for any time series (as the ones used in this paper) there exists a decomposition into a deterministic and stochastic component. Specifically, if $\left\{w_{t}\right\}_{t=1}^{T}$ designates a time series, this assumption implies that:

$$
w_{t}=\left(\alpha_{0}+\alpha_{1} t+\alpha_{2} \varphi_{t-1}\right)+\alpha_{3} Z_{t} ; E_{t-1}\left(Z_{t}\right)=0
$$

where $\varphi_{t}$ denotes the cyclical component of $w_{t}$ in period $t$ and $Z_{t}$ is some zero-mean (continuous) random variable which governs the behavior of the stochastic component. Taking expectations in the previous equation conditional on information available in period $t-1$ yields ${ }^{19}$ :

$$
E_{t-1}\left(w_{t}\right)=\alpha_{0}+\alpha_{1} t+\alpha_{2} \varphi_{t-1}
$$

which is the expression used for computing expectation terms of the endogenous variable and each of the exogenous variables.

Having discussed all relevant aspects of the R.E. model and the output equation (equation (20)), it is possible to proceed and analyze estimation results presented in Table No. 1. The system

$18 \quad \mathrm{u}_{\mathrm{t}}$ denotes a white noise term.

19 The time series used for obtaining output $\left(y_{t}\right)$, interest rate $\left(r_{t}\right)$, investment $\left(i_{t}\right)$, government's expenditure $\left(g_{t}\right)$, exports $\left(x_{t}\right)$, and real exchange rate $\left(Q^{t}\right)$ data were, respectively, the following: quarterly GDP original series (constant princes), nominal quarterly passive rate ("Tasa de interés Básica Pasiva" for its name in Spanish), quarterly gross capital formation (constant prices), quarterly government's final consumption expenditure (constant prices), quarterly exports of goods and services (constant prices), and a quarterly average of a multilateral real exchange rate index (Índice de Tipo de Cambio Efectivo Real Multilateral, or its acronym in Spanish ITCERM). Notice from (11) that the variable $\varphi_{t-1}$ is a one-period lagged cyclical component (in logs). In order to compute this regressor, the Hodrick-Prescott filter was utilized for decomposing $w_{t}$ into its cyclical $\left(\varphi_{t}\right)$ and trend components. Following Segura \& Vásquez (2011), a lambda parameter of 2250 was used to this end. For details see Segura, C., \& Vásquez, J. P. (2011). "Estimación del parámetro de suavizamiento del filtro de Hodrick y Prescott para Costa Rica". Next, the trend component of $\mathrm{w}_{\mathrm{t}}$ was regressed on $t$ and $\varphi_{\mathrm{t}-1}$ in order to estimate the alpha parameters for each time series. Therefore, $\mathrm{E}_{\mathrm{t}-1}\left(\mathrm{w}_{\mathrm{t}}\right)$ was computed by obtaining the vector of fitted values of equation (30) (i.e. using the previously estimated alpha parameters) for the endogenous variable and each of the exogenous variables used in this paper. Finally, the regressor $t=1, \ldots, 91$ corresponds to a generic variable with unitary increments. 
given by equations (20) and (22)-(27) was estimated as a simultaneous equation model using the Generalized Method of Moments (GMM). Various aspects support this choice. The first one is that because $E_{t}\left[\ln \left(y_{t+1}\right)\right]$ appears as an explanatory variable in (20) and as a dependent variable in (22), it is necessary to use a simultaneous equation method of estimation in order to obtain unbiased and consistent estimations robust to modifications in the assumed distribution of error terms (which is a priori unknown). This rules out the possibility of employing any Maximum Likelihood method for the task in question. The second fact is that the formula produced by the OLS estimation method is a particular case of GMM, which produces estimation rules based on orthogonality conditions. So addressing the estimation with GMM provides a more general estimation rule for obtaining the desired parameters. In third place, using the GMM estimation method allows further testing of the validity of the moment restrictions used for computing parameter estimators. By means of the specification test based in the J-statistic, it is possible to test if data cast evidence of an existing systematic violation to some set of moment restrictions assumed for computing GMM estimators. The fact of GMM estimation providing a method for testing the "validity" of the model implies a further inherent advantage of it. Another reason to consider for this is that in presence of heteroskedasticity, the GMM estimator brings efficiency gains in comparison to the Three Stage Least Squares (3SLS) estimator ${ }^{20}$.

\section{RESULTS}

TABLE 1

COSTA RICA: ESTIMATED PARAMETERS FOR EQUATIONS (20) AND (22)-(27), 1991:1 TO 2013:3

\begin{tabular}{lccccccc}
\hline \multicolumn{1}{c}{ Variable } & \multicolumn{5}{c}{ Equation } \\
& 20 & 22 & 23 & 24 & 25 & 26 & 27 \\
\hline Intercept & 1.5761 & 0.3541 & - & - & - & - & - \\
& $(0.0000)$ & $(0.0001)$ & - & - & - & - & - \\
$\mathrm{E}_{\mathrm{t}}\left[\ln \left(\mathrm{y}_{\mathrm{t}+1}\right)\right]$ & 0.6659 & - & - & - & - & - & - \\
& $(0.0000)$ & - & - & - & - & - & - \\
$\ln \left(1+r_{t+1}\right)$ & -0.0551 & - & - & - & - & - & - \\
& $(0.0002)$ & - & - & - & - & - & - \\
$\ln \left(i_{t}\right)$ & 0.0277 & - & - & - & - & - & - \\
& $(0.0000)$ & - & - & - & - & - & - \\
$\ln \left(g_{t}\right)$ & 0.0520 & - & - & - & - & - & - \\
& $(0.0247)$ & - & - & - & - & - & - \\
$\ln \left(x_{t}\right)$ & 0.1693 & - & - & - & - & - & - \\
& $(0.0000)$ & - & - & - & - & - \\
$\ln \left(Q_{t}\right)$ & -0.0406 & - & - & - & - & - \\
& $(0.0000)$ & - & - & - & - & - \\
$\mathrm{E}_{\mathrm{t}-1}\left[\ln \left(\mathrm{y}_{\mathrm{t}}\right)\right]$ & - & 0.8705 & - & - & - & -
\end{tabular}

Continued...

$20 \quad$ For details, see Greene (2003), pp. 410. The inclusion of equations (23)-(27) in the simultaneous equations estimation proved to be convenient for reasons of identification, i.e. by generating more moment conditions so that the system is overidentified. 


\begin{tabular}{lccccccc}
\hline \multicolumn{1}{c}{ Variable } & \multicolumn{5}{c}{ Equation } \\
& 20 & 22 & 23 & 24 & 25 & 26 & 27 \\
\hline & - & $(0.0000)$ & - & - & - & - & - \\
$\mathrm{E}_{\mathrm{t}-1}\left[\ln \left(1+r_{t}\right)\right]$ & - & -0.5040 & 0.9875 & - & - & - & - \\
& - & $(0.0000)$ & $(0.0000)$ & - & - & - & - \\
$\mathrm{E}_{\mathrm{t}-1}\left[\ln \left(i_{t}\right)\right]$ & - & 0.0243 & - & 1.0013 & - & - & - \\
& - & $(0.0277)$ & - & $(0.0000)$ & - & - & - \\
$\mathrm{E}_{\mathrm{t}-1}\left[\ln \left(g_{t}\right)\right]$ & - & 0.1105 & - & - & 1.0005 & - & - \\
& - & $(0.0000)$ & - & - & $(0.0000)$ & - & - \\
$\mathrm{E}_{\mathrm{t}-1}\left[\ln \left(x_{t}\right)\right]$ & - & -0.0220 & - & - & - & 1.0014 & - \\
& - & $(0.0008)$ & - & - & - & $(0.0000)$ & - \\
$\mathrm{E}_{\mathrm{t}-1}\left[\ln \left(Q_{t}\right)\right]$ & - & 0.0494 & - & - & - & - & 0.9994 \\
& - & $(0.0000)$ & - & - & - & - & $(0.0000)$ \\
Adjusted R & 0.9910 & 0.9999 & 0.9995 & 0.9997 & 0.9999 & 0.9995 & 0.9749 \\
squared & & 91 & 91 & 91 & 91 & 91 & 91 \\
Observations & 91 & & & 0.2570 & & & \\
J-statistic & & & & &
\end{tabular}

Note: numbers in "()" are p-values.

Source: BCCR. Time series.

Notice that two important outcomes must be highlighted from the estimation results ${ }^{21}$ in Table No. 1. The first one corresponds to the fact that the specification test based on the J-statistic does not reject the null hypothesis of all moment conditions being satisfied according to data. With a computed J-statistic of 0.257 , it is quite straightforward to verify for any number of degrees of freedom superior or equal to one, the associated p-value greatly exceeds any of the usual significance levels $1 \%, 5 \%$, and $10 \%{ }^{22}$. The second aspect refers to the overall motivation of this paper. Recall that the main purpose of this investigation is to estimate the effect that variations in the forecast of future output have on current output determination in Costa Rica. Estimation results for equation (20) show that the lambda coefficient associated to $E_{t}\left[\ln \left(y_{t+1}\right)\right]$ is 0.6659 . Notice that the estimated coefficient is statistically significant at any of the usual significance levels. Furthermore, its estimation constitutes significant economic implications in terms of the propagation system that determines the way the expectations updating mechanism (equations (22)-(27)) affects the determination of current output level (through equation (20)). Specifically, the result indicates that (controlling for other factors) a 1\% increment for the next quarter's expected real GDP is predicted to rise current quarterly real GDP level in an approximate $0,67 \%$ increase $\mathrm{e}^{23}$.

21 It should be indicated that data used for estimating the models corresponds to the official time series calculated by BCCR (Banco Central de Costa Rica, the acronym in Spanish for Central Bank of Costa Rica), which most of them may be consulted at the web address www.bccr.fi.cr.

22 Recall that the J-statistic converges asymptotically to a chi-square distribution with degrees of freedom equal to the number of overidentifying moment restrictions. 
As a final remark, a straightforward inspection at the performance of modeled output growth expectations is considered to supply additional evidence on the virtues and limitations of the computation methodology chosen for this variable in the present paper. To this end, Graph No. 1, Table No. 2, and Table No. 3 show some statistical results that arise from comparing the economy's expectations of output growth as computed for the model developed in this section (labeled "Predicted"), and the output growth expectations data gathered by the BCCR (labeled "BCCR"). The time series labeled as "Observed" corresponds to observed realizations of output growth rates throughout the period ${ }^{24}$.

TABLE 2

HYPOTHESIS TEST OF EQUAL VARIANCES, 2006:2 TO 2013:3

\begin{tabular}{|c|c|c|}
\hline Statistic & Predicted & BCCR \\
\hline Mean & 0.0461 & 0.0424 \\
\hline Variance & $3.3 \times 10^{-5}$ & $1.2 \times 10^{-4}$ \\
\hline Observations & 30 & 30 \\
\hline $\begin{array}{l}\text { Degrees of } \\
\text { freedom }\end{array}$ & 29 & 29 \\
\hline F-statistic & & 0.276 \\
\hline Critical value & & 0.537 \\
\hline
\end{tabular}

Note: $5 \%$ significance level.

Source: BCCR. Time series.

TABLE 3

HYPOTHESIS TEST OF EQUAL MEANS, 2006:2 TO 2013:3

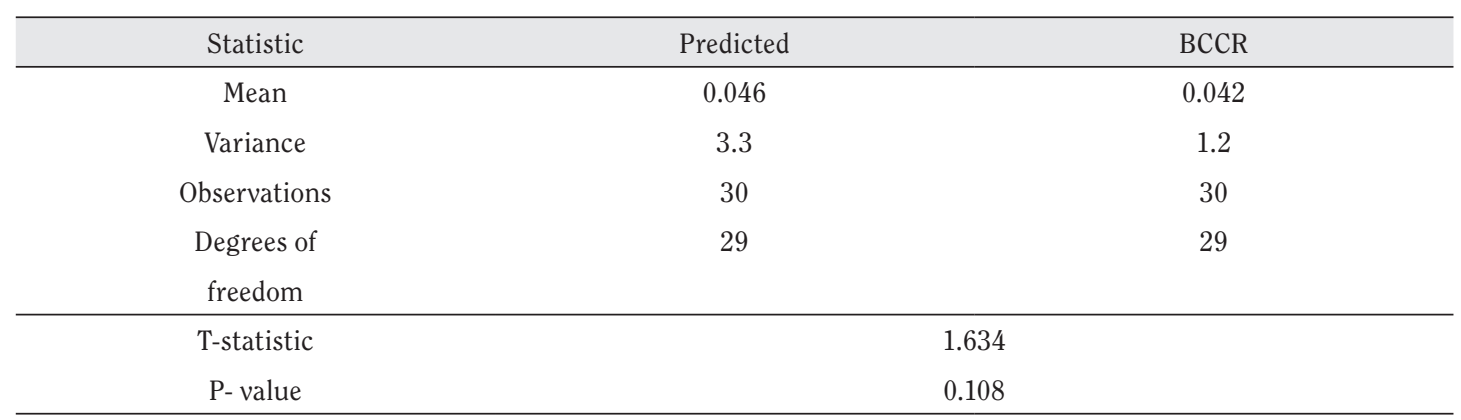

Source: BCCR. Time series.

24 These are annual expected and realized output growth rates, v.gr. output's growth rate forecast for period $2010 \mathrm{Q} 1$ (i.e. first quarter of 2010) conditional on information in 2009Q1, and so on. 


\section{GRAPH 1 \\ COSTA RICA: OUTPUT GROWTH RATE EXPECTATIONS AND REALIZED OUTPUT GROWTH RATES, 2006:2 TO 2013:3}

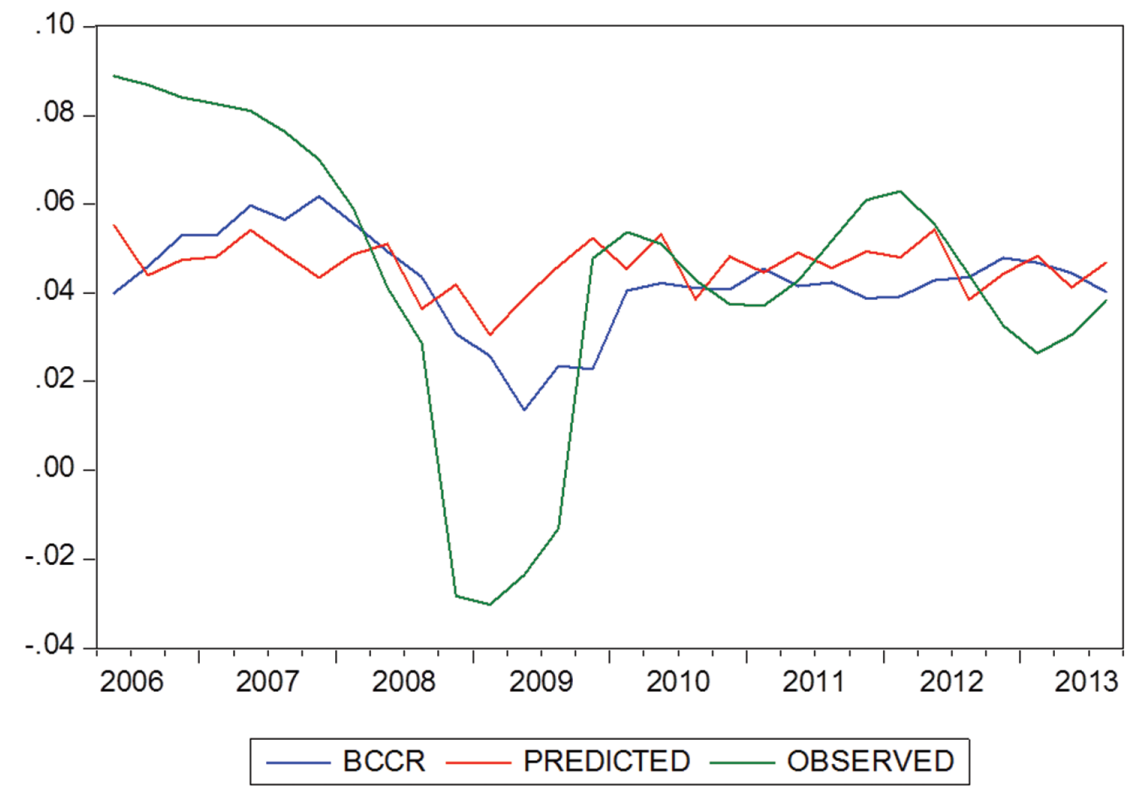

Source: BCCR. Time series.

Three aspects must be highlighted from the information above. The first one is that the computed time series of output growth expectations appears to be lowly correlated with data gathered by the BCCR about output growth forecasts (their correlation coefficient is slightly higher than 0.3). This fact is somehow represented in Graph No. 1. However, a second aspect to indicate is that the null hypothesis of equal means and variances between computed output growth expectations (i.e. "Predicted") and output growth expectations compiled by BCCR are not rejected in either case. This means that the chosen computation methodology replicates statistical features of output forecast formation process for the Costa Rican case, at least for the first two moments of its distribution function. The third and last indication needed to be highlighted is that the selected methodology replicates also the fact that expectations about output growth follow a time path much "smoother" than the time path of realized growth rates. This implication is related to the second highlighted aspect, as data from the "Predicted" and "BCCR" series does not reject the null hypothesis of equal variances, according to evidence from period 1991-2013 in Costa Rica. Despite the shortcoming implied by the apparently low correlation for the period 2006-2013 ${ }^{25}$, consideration of the other two aspects provides support of the convenience for using the chosen methodology in the present paper for computing output forecast ${ }^{26}$.

25 BCCR disposes of some information about future output growth expectations prior to 2006. All previous information to the year 2006 was computed using different methodologies, which makes it unfit for comparison with data compiled during and after the year 2006 . odology but not as a formal criterion for supporting/rejecting it. The reason is because: i) the sample set for expectations info compiled by BCCR doesn't contain data on years before 2006, and ii) there is nothing in the methodology used for gathering this data to guarantee that the whole economy's expectations of output growth will behave just like the forecasts of the surveyed units. 


\section{CONCLUDING REMARKS}

This paper develops an econometric model based on the Sidrauski-Brock framework developed by McCallum and Nelson (1997) and on a state-space representation of a R.E. model for future output's forecast, in order to estimate the effect that a $1 \%$ increase in the next quarter's expected GDP has on current quarterly GDP level (in real terms). The investigation concluded that this effect is predicted to equal, on average, an approximate $0.67 \%$ growth on current quarterly real GDP for each percent increase in next quarter's expected real GDP level. Furthermore, it must be noted that the fact that it is a positive effect is consistent with the theoretical proposal presented in section two. As previously discussed, this is justified because of the fact that usually economies exhibit consumption smoothing patterns over time, so that expected economic contractions induce agents to increase savings in order to transfer current income to the future and thus, to reduce their current aggregate spending. Notice this fact has important implications for fiscal and monetary policy design. For instance, suppose the monetary authority engages in a short run expansionary central bank policy so that it commits to maintain a quarterly average real GDP growth rate of $0.5 \%$ for the following four quarters. If credibility on the monetary authority's commitment is strong enough for agents to expect a $0.5 \%$ sustained real GDP growth for each of the following four quarters, then an approximate 3.85\% real GDP increase after the four quarters is predicted to be obtained (with respect to initial real GDP level) due to expectations variability alone (i.e. holding all other factors fixed). The lesson obtained from this estimation results is quite straightforward: effects of monetary policy on output variability go beyond the ones produced by agents' adjustments on their investment portfolios (i.e. adjustments due to agents' substitution of financial assets for others with different liquidity levels). As central banks' policies affect future income expectations, real effects on the economy may be generated due to modifications to saving decisions. Since expectations are not observable variables, this outcome could be often omitted at the time of policymaking, meanwhile the previous section showed it is economically significant. Finally, the econometric estimation showed that forecasts of all explanatory variables (in logs) included in equation (1) from section three have statistically significant influence for explaining future output's forecast variability. According to evidence from period 1991-2012, this conclusion highlights the importance of the expectations updating mechanism of economic variables described in this paper for explaining Costa Rican business cycle.

\section{REFERENCES}

Banco Central de Costa Rica. (2013). Programa Macroeconómico 2013-14. San José: Banco Central de Costa Rica.

Beaudry, P., \& Koop, G. (1993). Do recession permanently change output? Journal of Monetary Economics , 149-163.

Campbell, J., \& Mankiw, G. (1986). Are output fluctuations transitory. National Bureau of Economic Research .

Castrillo, D., \& Torres, C. (2010). Inflación externa relevante como un elemento a considerar en el establecimiento de la meta de inflación del Banco Central de Costa Rica. Banco Central de Costa Rica .

Castrillo, D., Mora, C., \& Torres, C. (2008). Mecanismos de transmisión de la política monetaria en Costa Rica: período 1991-2007. Banco Central de Costa Rica .

Cerra, V., \& Saxena, S. (2008). Growth dynamics: the mith of economic recovery. American Economic Review , 439-457.

Gourieroux, C., \& Monfort, A. (1997). Time series and dynamic models. Cambridge: Cambridge University Press. 
Greene, W. (2003). Econometric analysis. New Jersey: Pearson Education, Inc.

Gruen, D., \& Shuetrim, G. (1994). Internationalisation and the macroeconomy. International integration of the Australian economy , 309-363.

Judge, G., Griffiths, W., Hill, R., Lutkepohl, H., \& Lee, T. (1985). The theory and practice of econometrics. John Wiley \& Sons, Inc.

Lucas, R. (1973). Some international evidence on output-inflation trade-offs. The American Economic Review , 326-334.

McCallum, B., \& Nelson, E. (1997). An optimizing IS-LM specification for monetary policy and business cycle analysis. National Bureau of Economic Research .

Mishkin, F. (1982). Does anticipated monetary policy matter? An econometric investigation. Journal of Political Economy , 22-51.

Muñoz, E. (2006). La modelación macroeconómica en el Banco Central de Costa Rica en la transición del ancla cambiaria a metas de inflación. Banco Central de Costa Rica .

Murillo, J., Méndez, E., \& Prado, E. (2003). El tipo de cambio real de equilibrio de Costa Rica. San José: Departamento de Investigaciones Económicas, Banco Central de Costa Rica. .

Sargent, T. (1987). Dynamic macroeconomic theory. Cambridge: Harvard University Press.

Sargent, T., \& Wallace, N. (1976). Rational expectation and the theory of economic policy. Journal of monetary economics , 169-183.

Sayrs, L. (1989). Pooled Time Series Analysis. Sage, California.

Segura, C., \& Vásquez, J. P. (2011). Estimación del parámetro de suavizamiento del filtro de Hodrick y Prescott para Costa Rica. San José: Departamento de Investigación Económica, Banco Central de Costa Rica.

Sheffrin, S. (1983). Rational expectations. Cambridge University Press.

Woodford, M. (2001). The Taylor rule and optimal monetary policy. National Bureau of Economic Research . 
